\title{
Use of ionic liquids in synthesis of nanocrystals, nanorods and nanowires of elemental chalcogens
}

\author{
A THIRUMURUGAN \\ Chemistry and Physics of Materials Unit and DST Unit on Nanoscience, Jawaharlal Nehru Centre for Advanced \\ Scientific Research, Bangalore 560 064, India
}

MS received 1 February 2007

\begin{abstract}
Nanocrystals of elemental chalcogens have been synthesized solvothermally by using elemental chalcogen powder (Se and Te) and $\mathrm{NaBH}_{4}$ in imidazolium [BMIM]-based ionic liquids as solvents at $180-200^{\circ} \mathrm{C}$. Nanorods and nanowires of Se and Te have been obtained when polyethyleneglycol was used as a co-solvent. Se nanowires have been prepared by using an ionic liquid with a small amount of water at room temperature.

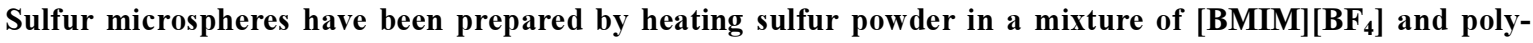
ethyleneglycol over the temperature range $150-250^{\circ} \mathrm{C}$. The nanostructures obtained are single crystalline in all the cases.
\end{abstract}

Keywords. Ionic liquids; nanostructures; chalcogens.

\section{Introduction}

Nanocrystals and nanorods of inorganic materials have been prepared by a variety of methods, especially those involving solvothermal and hydrothermal methods (Rao et al 2004; Schmid 2004; Burda et al 2005; Rao and Govindaraj 2006). In the last two to three years, there have been attempts to use ionic liquids as media for the synthesis of inorganic nanomaterials (Antonietti et al 2004; Zhou 2005). The low interface tension and the associated high nucleation rate as well as high thermal stability make ionic liquids attractive for carrying out the synthesis of nanostructures. However, there have been very few reports in the literature on the synthesis of inorganic nanomaterials such as elemental chalcogens and metal chalcogenides. Nanoparticles of Rh and Ir have been prepared by the reduction of the appropriate compound in 1-n-butyl-3methylimidazoliumhexafluorophosphate, $\left([\mathrm{BMIM}]\left[\mathrm{PF}_{6}\right]\right)$, in the presence of hydrogen (Fonseca et al 2003). Synthesis and functionalization of gold nanoparticles in ionic liquids are also reported, wherein the colour of gold nanoparticles can be tuned by changing the anion of ionic liquid (Itoh et al 2004). Single crystalline Te nanorods and nanowires have also been obtained by a microwave-assisted synthesis in liquid $n$-butylpyridiniumtetrafluoroborate and polyvinylpyrrolidone (Zhu et al 2004). So, it is considered as rewarding to explore the use of ionic liquids for the synthesis of elemental chalcogens.

Nanostructures of elemental chalcogens have been reported in the literature by a few workers. Thus, Gautam et

(thiru@jncasr.ac.in) al (2003) used a simple solution-based method involving the reaction of selenium powder with $\mathrm{NaBH}_{4}$ to prepare nanorods and nanowires of $t$-Se. Single crystalline $t$-Se nanowires were obtained by Gates et al (2002) by the reduction of selenious acid with excess hydrazine under refluxing conditions, while $\mathrm{Li}$ and Yam (2006) used ascorbic acid along with $\beta$-cyclodextrin for the reduction. $t$-Te nanorods, nanowires and nanobelts have been prepared by a solution-based method involving $\mathrm{NaBH}_{4}$ and sodium dodecylbenzenesulfonate starting with Te powder (Gautam and Rao 2004). Single crystalline Te nanotubes have been synthesized by the polyol process (Mayers and Xia 2002). Te nanorods, nanowires, and tubes have also been prepared by the reduction of $\mathrm{TeO}_{2}$ using polyvinylpyrrolidone or polyethylene glycol (Zhu et al 2006). To date, there is no report on synthesis of nanostructures of sulfur.

In this article, we report the results of our investigations using ionic liquids to prepare nanostructures of $\mathrm{S}$, Se and Te. We have examined the effects of changing the anion of the ionic liquid, as well as the presence of surfactants on the size and shape of the nanostructures of these materials.

\section{Experimental}

In order to prepare sulfur nanostructures, $0.025 \mathrm{~g}$ of sulfur powder was dispersed in $1.5 \mathrm{~mL}$ of polyethyleneglycol (PEG-600) and $1 \mathrm{~mL}$ of ionic liquid, 1-butyl-3-methylimidazolium tetrafluoroborate, ([BMIM] $\left.\left[\mathrm{BF}_{4}\right]\right)$. The mixture was heated in a $7 \mathrm{~mL}$ Teflon-lined stainless steel autoclave at $180^{\circ} \mathrm{C}$ for $12 \mathrm{~h}$. After cooling to room tempera- 
ture, the product was washed with water and ethyl alcohol several times.

In order to prepare Se nanostructures, several procedures were employed: (i) In one procedure, $0.01 \mathrm{~g}$ of Se powder and $0.05 \mathrm{~g}$ of $\mathrm{NaBH}_{4}$ were dispersed in $1 \mathrm{~mL}$ of ionic liquid 1-butyl-3-methylimidazolium hexafluorophosphate ([BMIM] $\left.\left[\mathrm{PF}_{6}\right]\right)$. The mixture was heated in a $7 \mathrm{~mL}$ Teflonlined stainless steel autoclave at $200^{\circ} \mathrm{C}$ for $10 \mathrm{~h}$. After cooling to room temperature, the product was washed with water and acetonitrile several times, (ii) in another preparation, $0.025 \mathrm{~g}$ of Se powder and $0.03 \mathrm{~g}$ of $\mathrm{NaBH}_{4}$ were dispersed in a mixture of $1 \mathrm{~mL}$ of PEG-600, $2 \mathrm{~mL}$ of [BMIM] $\left[\mathrm{BF}_{4}\right]$ and $2 \mathrm{~mL}$ of $\mathrm{H}_{2} \mathrm{O}$. The mixture was stirred and kept at room temperature for $48 \mathrm{~h}$. After cooling to room temperature, the product was washed several times with water and ethyl alcohol, (c) nanostructures were also prepared from a mixture of $0.025 \mathrm{~g}$ of Se powder and $0.03 \mathrm{~g}$ of $\mathrm{NaBH}_{4}$ dispersed in $1 \mathrm{~mL}$ of PEG-600, $2 \mathrm{~mL}$ of [BMIM] $\left[\mathrm{BF}_{4}\right]$ and $2 \mathrm{~mL}$ of $\mathrm{H}_{2} \mathrm{O}$. The mixture was stirred and heated at $75^{\circ} \mathrm{C}$ for $24 \mathrm{~h}$. After cooling to room temperature, the product was washed with water and ethyl alcohol and (d) a mixture of $0.01 \mathrm{~g}$ of Se powder and $0.05 \mathrm{~g}$ of $\mathrm{NaBH}_{4}$ was dispersed in $1 \mathrm{~mL}$ of PEG-600 and $1 \mathrm{~mL}$ of $[\mathrm{BMIM}]^{\circ}\left[\mathrm{PF}_{6}\right]$. The mixture was stirred and heated at $200^{\circ} \mathrm{C}$ for $10 \mathrm{~h}$. After cooling to room temperature, the product was washed several times with water and acetonitrile.

In order to prepare Te nanostructures, the following procedures were used: (i) Te nanoparticles were prepared from a mixture of $0.015 \mathrm{~g}$ of Te powder and $0.05 \mathrm{~g}$ of $\mathrm{NaBH}_{4}$ dispersed in $1 \mathrm{~mL}$ of $[\mathrm{BMIM}]\left[\mathrm{PF}_{6}\right]$. The mixture was heated in a $7 \mathrm{~mL}$ Teflon lined stainless steel autoclave at $200^{\circ} \mathrm{C}$ for $10 \mathrm{~h}$. After cooling to room temperature, the product was washed several times with water and acetonitrile, (ii) in a second set of reactions, a mixture of $0.015 \mathrm{~g}$ of Te powder and $0.05 \mathrm{~g}$ of $\mathrm{NaBH}_{4}$ was dispersed in $2 \mathrm{~mL}$ of PEG- 600 and $2 \mathrm{~mL}$ of $\left[\mathrm{BMIM}^{2}\left[\mathrm{PF}_{6}\right]\right.$. The mixture was heated in a $7 \mathrm{~mL}$ Teflon lined stainless steel autoclave at $200^{\circ} \mathrm{C}$ for $10 \mathrm{~h}$. After cooling to room temperature, the product was washed several times with water and acetonitrile and (iii) in another set of reactions, a mixture of $0.015 \mathrm{~g}$ of Te powder, $0.02 \mathrm{~g}$ of cetyltrimethylammoniumbromide (CTAB) and $0.05 \mathrm{~g}$ of $\mathrm{NaBH}_{4}$ was dispersed in $2 \mathrm{~mL}$ of $[\mathrm{BMIM}]\left[\mathrm{PF}_{6}\right]$. The mixture was heated in a $7 \mathrm{~mL}$ Teflon-lined stainless steel autoclave at $200^{\circ} \mathrm{C}$ for $10 \mathrm{~h}$. After cooling to room temperature, the product was washed several times with water and acetonitrile.

TEM images of the nanostructures were obtained by taking a drop of ethanol solution on the holey carboncoated $\mathrm{Cu}$ grids. The grids were allowed to dry in air and examined by using a JEOL (JEM3010) microscope operating with an accelerating voltage of $300 \mathrm{kV}$. The nanostructures were also characterized by powder X-ray diffraction (XRD) using a Phillips X'Pert diffractometer employing the Bragg-Brentano configuration. PL experiments were performed using a Perkin-Elmer LS 50B luminescence spectrophotometer fitted with a Xenon lamp excitation source (200-900 nm). Absorption spectra were recorded using a Perkin-Elmer Lambda $900 \mathrm{UV} /$ VIS/NIR spectrophotometer (200-3300 nm). Field emission SEM images of nanostructures were recorded by taking a drop of ethanol solution on the aluminum sample holder.

\section{Results and discussion}

Dissolving sulfur powder in [BMIM] $\left[\mathrm{BF}_{4}\right]$ or polyethyleneglycol alone and heating the solution to $200^{\circ} \mathrm{C}$ did not yield in any nanostructures. Addition of $\mathrm{NaBH}_{4}$ to the solution had no effect. However, heating sulfur powder in a mixture of [BMIM] $\left[\mathrm{BF}_{4}\right]$ and polyethyleneglycol over a temperature range of $150-250^{\circ} \mathrm{C}$ resulted in the formation of sulfur microspheres rather than any nanostructures. In figure 1(a), we show a SEM image of the sulfur microspheres prepared in a mixture of $[\mathrm{BMIM}]\left[\mathrm{BF}_{4}\right]$ and polyethyleneglycol at $180^{\circ} \mathrm{C}$ for $12 \mathrm{~h}$. The microspheres are reasonably monodisperse with an average diameter of $18 \mu \mathrm{m}$. The microspheres are crystalline and the powder XRD pattern could be indexed based on the orthorhombic $(F d d d)$ space group. Heating Se powder in a mixture of $\mathrm{NaBH}_{4}$ and $[\mathrm{BMIM}]\left[\mathrm{PF}_{6}\right]$ at $200^{\circ} \mathrm{C}$ for $10 \mathrm{~h}$ gives rise to Se particles and flower-like structures as shown in the SEM image in figure 1(b). These Se structures are crys-

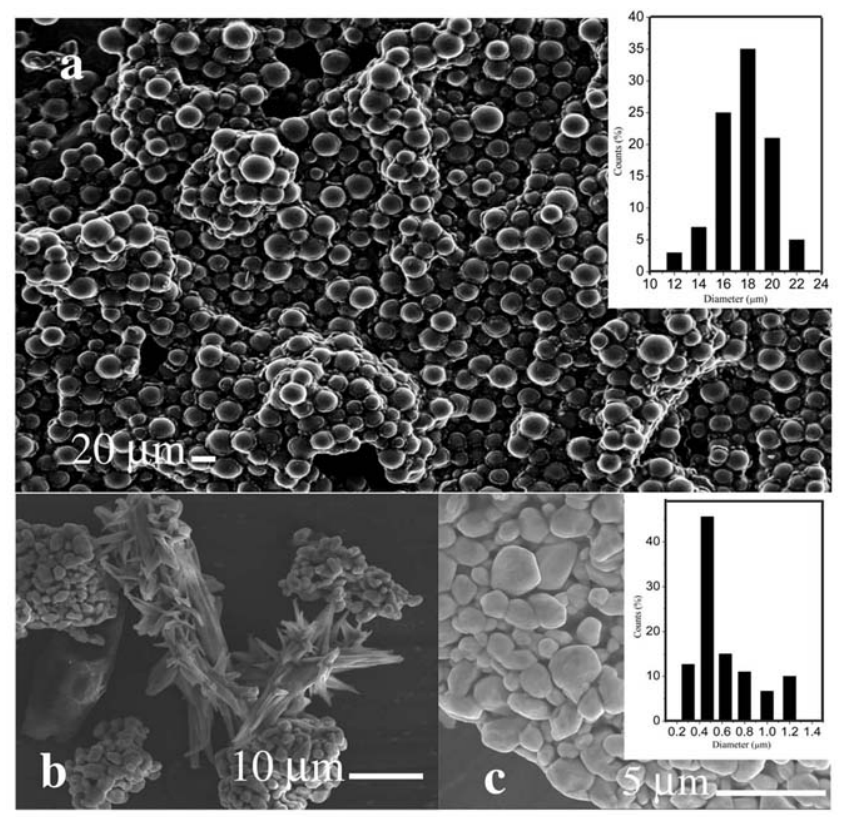

Figure 1. (a) SEM image of $\mathrm{S}$ microspheres prepared in a mixture of $[\mathrm{BMIM}]\left[\mathrm{BF}_{4}\right]$ and polyethylene glycol at $180^{\circ} \mathrm{C}$ for $12 \mathrm{~h}$. Inset shows the size distribution histogram, (b) SEM image of Se particles and flower like structures prepared in a mixture of $[\mathrm{BMIM}]\left[\mathrm{PF}_{6}\right]$ and $\mathrm{NaBH}_{4}$ at $200^{\circ} \mathrm{C}$ for $10 \mathrm{~h}$ and (c) SEM image of $\mathrm{Te}$ microcrystals prepared in a mixture of [BMIM] $\left[\mathrm{PF}_{6}\right]$ and $\mathrm{NaBH}_{4}$ at $200^{\circ} \mathrm{C}$ for $10 \mathrm{~h}$. Inset shows the size distribution histogram. 
talline and the powder XRD pattern could be indexed based on the hexagonal $\left(P 3_{1} 2_{1}\right)$ space group. Under similar conditions, heating Te powder in $[\mathrm{BMIM}]\left[\mathrm{PF}_{6}\right]$ in the presence of $\mathrm{NaBH}_{4}$ gives rise to Te particles with an average diameter of $450 \mathrm{~nm}$. The particles are crystalline and the powder XRD pattern could be indexed based on the hexagonal $\left(P 3_{1} 2_{1}\right)$ space group. Figure $1(\mathrm{c})$ shows a SEM image of the Te microcrystals obtained in this manner.

A mixture of Se nanowires and dendritic structures of particles was obtained by keeping Se powder in a mixture of $[\mathrm{BMIM}]\left[\mathrm{BF}_{4}\right]$, polyethyleneglycol, $\mathrm{NaBH}_{4}$ and $\mathrm{H}_{2} \mathrm{O}$ at $30^{\circ} \mathrm{C}$ for $48 \mathrm{~h}$. The wires have a diameter of around $150 \mathrm{~nm}$ and of $10 \mu \mathrm{m}$ length. The particles in the dendritic structures are crystalline and have an average diameter of $100 \mathrm{~nm}$. Figure 2(a) shows a SEM image of the Se nanowires, with the inset showing dendritic structures. The above reaction mixture when heated at $75^{\circ} \mathrm{C}$ for $24 \mathrm{~h}$, gave aggregates of crystalline plate-like structures. Figure 2(b) shows a SEM image of plate-like structures prepared. Rod-like structures of Se were obtained, when Se powder was heated in a mixture of $\left[\mathrm{BMIM}\left[\mathrm{PF}_{6}\right]\right.$, polyethyleneglycol and $\mathrm{NaBH}_{4}$ at $200^{\circ} \mathrm{C}$ for $10 \mathrm{~h}$. The rods are crystalline and reasonably monodisperse with an average diameter of $500 \mathrm{~nm}$ and a length of 2-3 $\mu \mathrm{m}$. Figure 2(c) shows a SEM image of the rod-like structures. The powder XRD pattern of these Se nanostructures could be indexed based on the hexagonal $\left(P 3_{1} 2_{1}\right)$ space group.

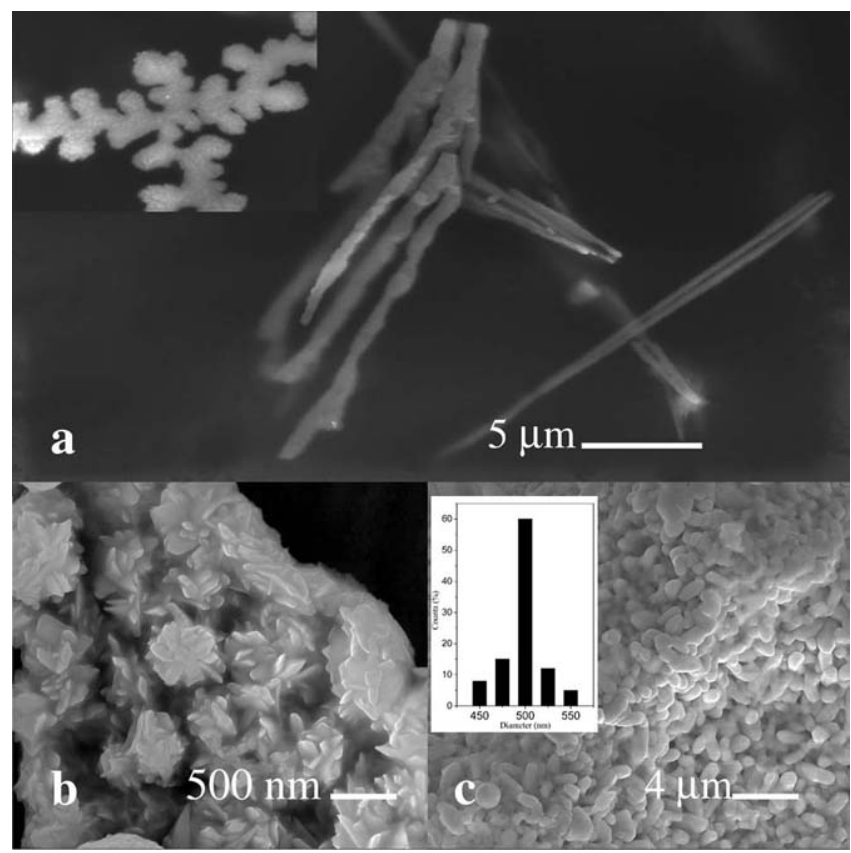

Figure 2. (a) SEM image of Se nanowires and the inset shows dendritic structure of Se particles prepared in a mixture of [BMIM] $\left[\mathrm{BF}_{4}\right]$, polyethyleneglycol, $\mathrm{NaBH}_{4}$ and $\mathrm{H}_{2} \mathrm{O}$ at room temperature for $48 \mathrm{~h}$, (b) SEM image of Se plate-like structures prepared in $[\mathrm{BMIM}]\left[\mathrm{BF}_{4}\right]$, polyethyleneglycol, $\mathrm{NaBH}_{4}$ and $\mathrm{H}_{2} \mathrm{O}$ at $75^{\circ} \mathrm{C}$ for $24 \mathrm{~h}$ and (c) SEM image of Se rod-like structures prepared in a mixture of $[\mathrm{BMIM}]\left[\mathrm{PF}_{6}\right]$, polyethyleneglycol and $\mathrm{NaBH}_{4}$ at $200^{\circ} \mathrm{C}$ for $10 \mathrm{~h}$. Inset shows the size distribution histogram.
Te nanowires with an average thickness of $75 \mathrm{~nm}$ and several microns in length were obtained when Te powder was

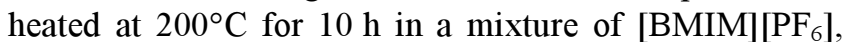
polyethyleneglycol and $\mathrm{NaBH}_{4}$. Figure 3(a) shows a SEM image of the Te nanowires and figure 3(b) shows a TEM image. A high-resolution electron microscopic (HREM) image of a single nanowire is shown in figure 3(c). The inset in figure 3(c) shows the selected area electron di-

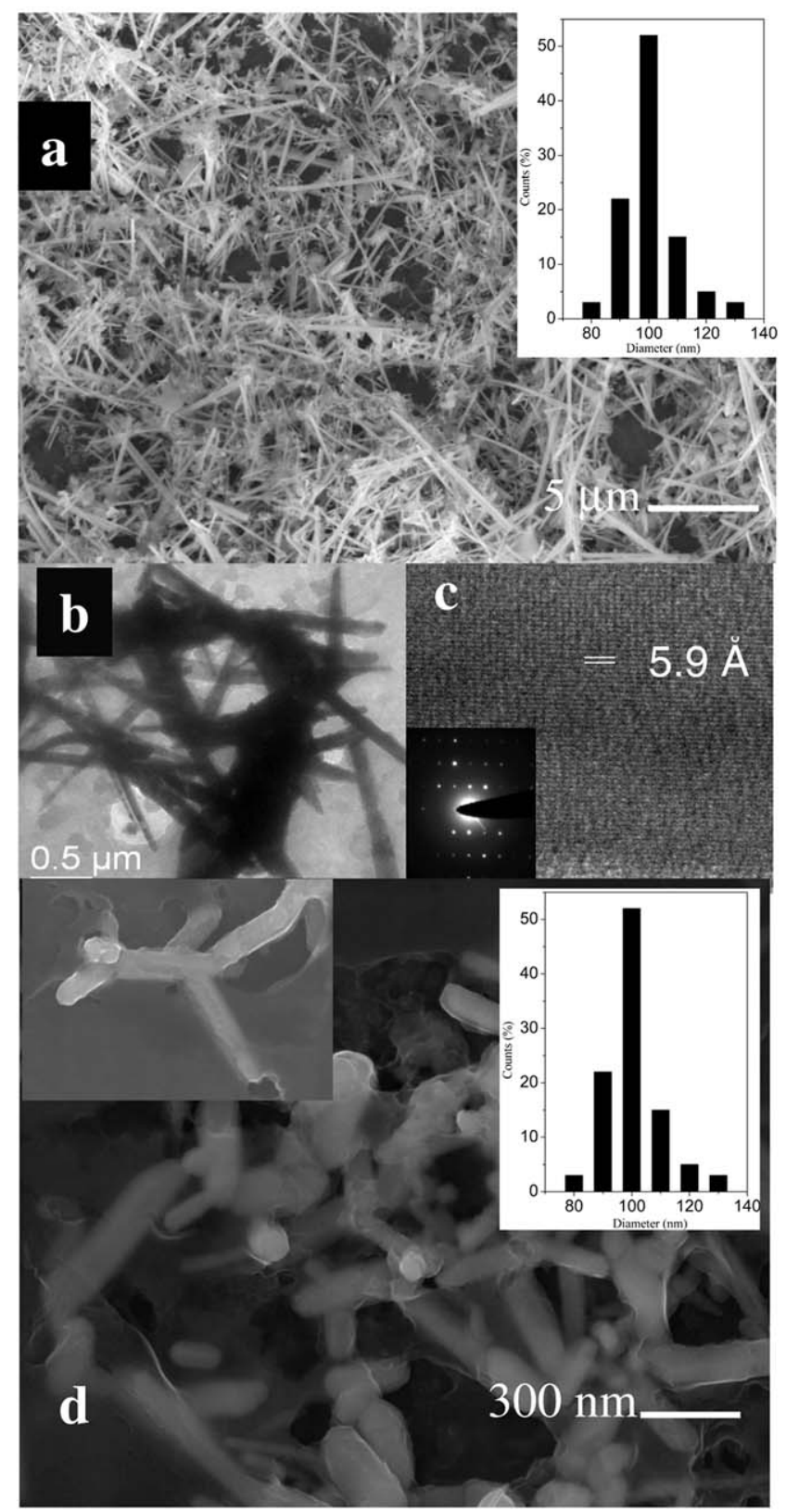

Figure 3. (a) SEM image of Te nanowires prepared in a mixture of $[\mathrm{BMIM}]\left[\mathrm{PF}_{6}\right]$, polyethylene glycol and $\mathrm{NaBH}_{4}$ at $200^{\circ} \mathrm{C}$ for $10 \mathrm{~h}$. Inset shows the size distribution histogram, (b) TEM images of Te nanowires, (c) HREM image of a single nanowire and the inset shows electron diffraction patterns and (d) SEM image of Te nanorods prepared in a mixture of [BMIM] $\left.\mathrm{PF}_{6}\right]$, $\mathrm{CTAB}$ and $\mathrm{NaBH}_{4}$ at $200^{\circ} \mathrm{C}$ for $10 \mathrm{~h}$. Inset shows the Yjunctions and the size distribution histogram. 
ffraction (SAED) pattern with a lattice spacing of $5.9 \AA$ corresponding to the (001) planes of the hexagonal Te structure. When the polyethyleneglycol was replaced by CTAB in the reaction mixture, Te nanorods with an average diameter of $100 \mathrm{~nm}$ and a length of 300-400 nm were obtained under similar reaction conditions. Few Yjunctions were also found in the product. In figure 3(d), we show a SEM image of the Te nanorods obtained from a mixture of [BMIM] $\left[\mathrm{PF}_{6}\right], \mathrm{CTAB}$ and $\mathrm{NaBH}_{4}$ at $200^{\circ} \mathrm{C}$ after $10 \mathrm{~h}$. The insets show the $\mathrm{Y}$-junctions and the size distribution histogram. All the Te nanostructures are crystalline and the powder XRD patterns could be indexed based on the hexagonal $\left(P 3_{1} 2_{1}\right)$ space group.

\section{Conclusions}

Preparation of nanowires and nanorods of $\mathrm{Se}$ and $\mathrm{Te}$, based on the aqueous solution method at room temperature by using elemental chalcogen powder and $\mathrm{NaBH}_{4}$ have been reported in the literature. We failed to obtain nanowires of Se and $\mathrm{Te}$ at room temperature using an ionic liquid alone. However, we could obtain Se nanowires by using ionic liquid with a small amount of water at room temperature. We could synthesize other nanostructures of elemental chalcogens at $180-200^{\circ} \mathrm{C}$. Sulfur microspheres could be prepared by heating sulfur powder in a mixture of $[\mathrm{BMIM}]\left[\mathrm{BF}_{4}\right]$ and polyethyleneglycol.

\section{Acknowledgements}

The author thanks Prof. C N R Rao for suggesting the problem and constant support. The author also thanks the
Council of Scientific and Industrial Research (CSIR), Government of India, for the award of a Senior Research Fellowship.

\section{References}

Antonietti M, Kuang D, Smarsly B and Zhou Y 2004 Angew. Chem. Int. Ed. $\mathbf{4 3} 4988$

Burda C, Chen X, Narayanan R and El-Sayed M A 2005 Chem. Rev. 1051025

Fonseca G S, Umpierre A P, Fichtner P F P, Teixeira S R and Dupont J 2003 Chem. Eur. J. 93263

Gates B, Mayers B, Cattle B and Xia Y 2002 Adv. Funct. Mater. 12219

Gautam U K and Rao C N R 2004 J. Mater. Chem. 142530

Gautam U K, Nath M and Rao C N R 2003 J. Mater. Chem. 135 2845

Itoh H, Naka K and Chujo Y 2004 J. Am. Chem. Soc. 126 3026

Li Q and Yam V W-W 2006 Chem. Commun. 1006

Mayers B and Xia Y 2002 Adv. Mater. 14279

Rao C N R and Govindaraj A 2006 Nanotubes and nanowires: RSC series on nanoscience and nanotechnology (Cambridge: $\mathrm{RSC})$

Rao C N R, Mueller A and Cheetham A K (eds) 2004 The chemistry of nanomaterials (Weinheim: Wiley-VCH)

Schmid G (ed.) 2004 Nanoparticles: Theory to application (Weinheim: Wiley-VCH)

Zhou Y 2005 Curr. Nanosci. 135

Zhu Y-J, Wang W-W, Qi R-J and Hu X-L 2004 Angew. Chem. Int. Ed. 431410

Zhu Y-J, Hu X-L and Wang W-W 2006 Nanotechnology 17 645 